\title{
Vascular factors altered in glucose-treated mesangial cells and diabetic glomeruli. Changes in vascular factors impair endothelial cell growth and matrix
}

\author{
Ashok K Singh ${ }^{1}$, Krishnamurthy P Gudehithlu ${ }^{1}$, Alfredo A Pegoraro ${ }^{1}$, Gogi K Singh ${ }^{1}$, Khaja \\ Basheerudin $^{2}$, Robert B Robey ${ }^{3}$, Jose AL Arruda ${ }^{3,4}$ and George Dunea ${ }^{1,3,4}$ \\ ${ }^{1}$ Hektoen Institute for Medical Research, Chicago, IL, USA; ${ }^{2}$ Department of Pathology, Cook County Hospital, \\ Chicago, IL, USA; ${ }^{3}$ Section of Nephrology, University of Illinois at Chicago and VAMC, West Side Division, \\ Chicago, IL, USA and ${ }^{4}$ Divison of Nephrology, Cook County Hospital, Chicago IL, USA
}

\begin{abstract}
We studied the effect of a high glucose (HG) environment on the vascular factors that are secreted by mesangial cells, and regulate endothelial growth and mesangial matrix deposition. To this effect, we measured the vascular factors in the glomeruli of streptozotocin-induced diabetic kidneys and in mesangial cells exposed to a HG concentration. We then transferred the media of mesangial cells previously exposed to high glucose to cultured endothelial cells to study the effects on endothelial growth, matrix formation, and in vitro capillary proliferation. In 1-week diabetic kidneys, glomerular vascular endothelial growth factor (VEGF) and angiopoietin-1 were inhibited by 38 and $57 \%$, respectively, but angiopoietin-2 was increased by $318 \%$. We found similar results in mesangial cells exposed to HG. There was a decrease of VEGF $(50 \%$ by enzyme immunoassay, $27 \%$ by mRNA), decrease of angiopoietin-1 (65\% by mRNA), and a much greater increase of angiopoietin-2 $(280 \%$ by immunoassay, $523 \%$ by mRNA). Compared to controls, the media of mesangial cells previously exposed to HG impaired endothelial cell growth by $61 \%$, increased extracellular matrix by $100 \%$, and decreased capillary formation by $90 \%$. We conclude that high ambient glucose alters the secretion of vascular factors elaborated by mesangial cells, resulting in an expansion of the endothelial cell matrix and disruption of capillary structure.

Laboratory Investigation (2004) 84, 597-606, advance online publication, 29 March 2004; doi:10.1038/labinvest.3700082
\end{abstract}

Keywords: VEGF; angiopoietin; mesangial cells; endothelial cells; high glucose; diabetes; matrix

The mesangial cell plays a critical role in the pathogenesis of diabetic nephropathy by promoting the deposition of matrix that ultimately results in the loss of the glomerulus. In earlier studies, high ambient glucose has been shown to stimulate mesangial cells to lay down excessive amounts of matrix, both by increasing matrix synthesis ${ }^{1}$ and by decreasing degradation. ${ }^{2}$ This process is preceded and sustained by increased TGF- $\beta 1$ and angiotensinII expression in cultured mesangial cells ${ }^{3-6}$ and also in the streptozotocin diabetic rat kidney. ${ }^{7}$ Other mechanisms that may cause matrix accumulation are not fully understood.

Correspondence: AK Singh, PhD, Hektoen Institute for Medical Research, 2100 Harrison Street, Chicago IL 60612, USA.

E-mail: singashok@aol.com

Received 4 August 2003; revised 21 January 2004; accepted 25 January 2004; published online 29 March 2004
It is becoming increasingly accepted that vascular factors such as vascular endothelial growth factor (VEGF) and angiopoietins, although important for development, are also involved in the maintenance of the endothelial cell, its matrix, and the capillary structure in the postnatal life and adulthood. ${ }^{8,9}$ The pericytes (a cell of smooth muscle lineage) surrounding the endothelial cell synthesize these factors that act on the endothelial cell ${ }^{10,11}$ through receptors on the cell surface. Thus, a paracrine relationship exists between the endothelial cell and other neighboring cells, as was recently demonstrated in the developing and the postnatal mouse kidney. ${ }^{12,13}$ Conceptually, in healthy vascular tissue provascular factors (VEGF, angiopoietin-1) predominate, while in regressing or scarring vascular tissues the antivascular factors (angiopoietin-2) prevail. ${ }^{14}$ In the glomerulus it is not clear which cell type acts as the pericyte, since both the visceral epithelial cells and the mesangial cells (specialized smooth muscle 
cells) are in direct contact with the capillaries. Indeed, VEGF synthesis has been demonstrated in mesangial cells ${ }^{15-19}$ as well as in visceral epithelial cells (podocytes). ${ }^{20-26}$ There are limited data on the localization of angiopoietins in the adult kidney, although in the developing kidney angiopoietins-1 and -2 have been localized to the glomerulus, including the mesangium. ${ }^{12,13}$ In one study on an adult human kidney, angiopoietin-1 was immunohistologically localized to the podocytes. ${ }^{23}$ Thus, it appears that both the glomerular epithelial and the mesangial cell synthesize vascular factors, and may be serving the functions of a pericyte in maintaining glomerular capillaries.

We hypothesized that in disease states such as diabetes, the normal physiological relationship between the pericyte (like the mesangial cell) and endothelial cells is disrupted. High glucose (HG) could modulate the synthesis of vascular factors from the mesangial cells, in a manner that would adversely affect the growth and expand the matrix of endothelial cells, thereby damaging the capillary structure. To test this hypothesis, we measured VEGF $_{165}$, angiopoietins-1, and -2 in cultured rat mesangial cells exposed to HG. We then tested the effects of mesangial media containing these altered vascular factors in vitro on endothelial cell proliferation, matrix accumulation, and capillary formation.

\section{Materials and methods}

\section{Culture of Primary Rat Mesangial Cells}

Primary cultures of mesangial cell were obtained by plating disaggregated glomeruli into culture dishes in RPMI 1640 medium with $20 \%$ fetal bovine serum (FBS) supplemented with glutamine ( $4 \mathrm{mM})$, insulin $(0.67 \mathrm{U} / \mathrm{ml})$, penicillin $(100 \mathrm{U} / \mathrm{ml})$, streptomycin $(100 \mu \mathrm{g} / \mathrm{ml})$ and HEPES $(15 \mathrm{mM})$ buffer and differentially characterized as described earlier. ${ }^{2,4}$ The cultures were incubated at $37^{\circ} \mathrm{C}$ in a humidified $5 \%$ $\mathrm{CO}_{2}-95 \%$ air atmosphere. Media were changed every 3-4 days until the cells reached $100 \%$ confluence (after 20-25 days).

\section{Culture of Endothelial Cells}

Starter cultures of human umbilical vein endothelial cells (HUVEC) were obtained from Clonetics (San Diego, CA, USA). Cultures were maintained in a basal medium (EBM, Clonetics) supplemented with a growth factor mix EGM that contains $10 \mathrm{ng} / \mathrm{ml}$ epidermal growth factor, $1.0 \mu \mathrm{g} / \mathrm{ml}$ hydrocortisone, $12.0 \mu \mathrm{g} / \mathrm{ml}$ bovine brain extract, gentamicin (50 ng/ $\mathrm{ml})$, amphotericin B $(50 \mu \mathrm{g} / \mathrm{ml})$, and $2 \%$ FBS as recommended and supplied by the manufacturer (Clonetics). Cells were passaged using calcium and magnesium-free HEPES-buffered saline solution. Endothelial cells were characterized by phase- contrast morphology, the presence of Von Willebrand's factor (Factor VIII) antigen, and by their ability to endocytose acetylated LDL. Cells between passages five and 10 were used for all experiments.

\section{Treatment of Mesangial Cells with HG and Preparation of Cell-free Media and Cell Extracts}

Confluent layers of rat mesangial cells growing in T-75 culture flasks were used. The medium was replaced with fresh serum-free RPMI medium that contained $10 \mathrm{mM}$ glucose (normal glucose control (NG)) or $25 \mathrm{mM}$ glucose (high glucose, HG) or $10 \mathrm{mM}$ glucose $+15 \mathrm{mM}$ mannitol (high mannitol, HM, osmotic control). The cells were incubated at $37^{\circ} \mathrm{C}$ in $5 \% \mathrm{CO}_{2}-95 \%$ air for 4 days. The cell-free medium was collected, aliquoted, and stored at $-20^{\circ} \mathrm{C}$ for VEGF $_{165}$ assay. The remaining sample was dialyzed, lyophilized, and reconstituted to $1 / 20$ of the original volume for assays for angiopoietin-1 and -2 . The cell layers were extracted for total RNA according to the method of using the guinidinium isothiocyanate and phenol-chloroform-based phase separation technique (Total RNA isolation kit, Promega, Madison, WA, USA). ${ }^{27}$

The viability of cells after 4 days of incubation remained unchanged (viability by trypan blue dye exclusion $\mathrm{NG}=98.3 \pm 1.6 \%$; $\mathrm{HG}=98.8 \pm 0.9 \%$; and $\mathrm{HM}=98.5 \pm 2.1 \%, n=8)$.

\section{Enzyme Immunoassays for $\mathrm{VEGF}_{165}$, and Angiopoietins-1, -2}

A sandwich enzyme immunoassay was set up for measuring $\mathrm{VEGF}_{165}$ using the Quantikine ${ }^{\mathrm{TM}}$ murine VEGF assay kit from R\&D Systems (Minneapolis, MN, USA). Henceforth, the mention of VEGF in the text will refer to $\mathrm{VEGF}_{165}$.

Competitive enzyme immunoassays were developed for angiopoietins - 1 and -2 by sensitizing 96well polyvinyl plate wells with $1 \mu \mathrm{g} / \mathrm{ml}$ of purified angiopoietin -1 or -2 peptides $(200 \mu \mathrm{l} /$ well) (Alpha Diagnostics, Inc., San Antonio, TX, USA) in $50 \mathrm{mM}$ borate buffer $\mathrm{pH} 10.5$ overnight at $4^{\circ} \mathrm{C}$. Following blocking with $200 \mu \mathrm{l} /$ well of $5 \%$ bovine serum albumin (BSA) - 1\% Tween-20 in phosphate (10 mM)-buffered saline ( $\mathrm{NaCl} 125 \mathrm{mM}$ ), pH 7.4 (PBS) the wells were incubated with anti-angiopoietin-1 (1:1000) or -2 (1:5000) (Alpha Diagnostics, Inc., San Antonio, TX, USA) and either standard concentrations of purified peptides (Alpha Diagnostics, Inc., San Antonio, TX, USA) or assay samples at $4^{\circ} \mathrm{C}$ overnight at room temperature. After washing, the wells were incubated with $200 \mu \mathrm{l} /$ well of anti-rabbit IgG - horseradish peroxidase conjugate diluted $1: 10,000$ in the BSA-Tween-PBS diluent. Following $1 \mathrm{~h}$ of incubation and washing, the bound conjugate was developed using $200 \mu \mathrm{l} /$ well of substrate solution containing $0.2 \mathrm{mg} / \mathrm{ml}$ of $O$-phenylenediamine hydrochloride $-0.03 \% \mathrm{H}_{2} \mathrm{O}_{2}$ in $\mathrm{PBS}$ at room 
temperature for $30 \mathrm{~min}$. The reaction was stopped by addition of $50 \mu \mathrm{l} /$ well of $5 \mathrm{~N} \mathrm{H}_{2} \mathrm{SO}_{4}$ and read in an ELISA reader (Molecular Devices, Sunnyvale, CA, USA). Angiopoietin levels were determined from the standard curve. VEGF and angiopoietin-1, 2 levels were normalized by the protein content of the cell layer. Protein was determined by the Bradford method (Biorad, Hercules, CA, USA) following detergent extraction of the cell layer.

\section{Detection of mRNA Transcripts by Reverse Transcriptase - Polymerase Chain Reaction (RT-PCR)}

The procedure was carried out in one step using 500 ng of total RNA according to the Promega RTPCR system (Promega, Madison, WA, USA). The system uses AMV Reverse Transcriptase from Avian Myeloblasotosis Virus for first strand synthesis at $48^{\circ} \mathrm{C}$ and thermostable Tfl DNA polymerase from Thermus flavus for second strand cDNA synthesis and DNA amplification. $\beta$-actin amplification was performed from the total RNA preparations (50 ng) as a control. The amplification was carried for 10-40 cycles. cDNA bands were quantitated as the ratio of : band density/ $\beta$-actin band density by image analysis of photographic prints (Scion Image software, Scion Corporation, Frederick, MD, USA). The primer sets and temperature parameters for each product were: Rat VEGF - sequence 99-446, sense: GGAGCAGA AAGCCCATGAAG-3', anti-sense: 5'-GCTCTGAACA AGGCTCACAG- $3^{\prime} .{ }^{28}$ Mouse angiopoietin -1 - sequence 1411-1654, sense: $5^{\prime}$-AGGCAGTACATGCTGAG GATTG-3', antisense: 5'-CGAACCACCAACCTCCTG TTAG- $3{ }^{\prime}{ }^{29}$ Rat angiopoietin $-2-$ sequence $4-406$, sense: $5^{\prime}$-GAGTACAAAGAGGGCTTC- ${ }^{\prime}$, antisense: $5^{\prime}$-ACCACTTGATACCGTTG- $3^{\prime} .^{30}$ Rat $\beta$-actin - sequence - $2725-3133$, sense: 5'-TCATGAAGTGTGAC GTTGACATCCGT-3', antisense: 5'-CCTAGAAGCAT TTGCGGTGCACGATG- $3^{\prime} .^{31}$ Temperatures: denaturation $94^{\circ} \mathrm{C}-$ annealing $60^{\circ} \mathrm{C}$ - extension $68-72^{\circ} \mathrm{C}$.

\section{Preparation of Conditioned Media of Mesangial Cells for Testing on Endothelial Cells}

To test whether HG may affect endothelial cell growth and its matrix via vascular factors secreted by mesangial cells, we examined the effect of conditioned medium harvested from mesangial cells exposed to HG on endothelial proliferation $\left({ }^{3} \mathrm{H}-\right.$ thymidine uptake), matrix accumulation, and in vitro capillary formation. Cell-free media were collected from mesangial cells incubated for 4 days with NG or HG, processed to equalize them in levels of gelatinases, glucose, salts and TGF- $\beta 1$, and finally reconstituted in the endothelial cell media (ECM) as described below. The mesangial media were processed because in addition to the differences in the content of vascular factors in the NG and HG the media would also contain unequal amounts of other nonvascular factors such as glucose, TGF- $\beta 1$ and gelatinase that can affect cell growth and matrix of other cells. Further, it was necessary to make up the conditioned media finally in the special endothelial cell media (EGM) as endothelial cells (HUVEC) require special factors for growth not present in the mesangial cell media (RPMI). To assure equalization of the nonvascular factors (glucose, TGF- $\beta 1$ and gelatinase), these were measured in the original and reconstituted media.

As observed before ${ }^{2}$ gelatinase activity (measured by fluorescent assay and zymography) was $50 \%$ less in $\mathrm{HG}(21 \mathrm{U} / \mathrm{ml})$ compared to $\mathrm{NG}(44 \mathrm{U} / \mathrm{ml})$. In order to remove and equalize the gelatinase amount in the two media, the media were incubated with an insolubilized gelatin affinity matrix (Sepharosegelatin gel, Pierce Chemical, Rockford, IL, USA) for $2 \mathrm{~h}$ at $4^{\circ} \mathrm{C}$ followed by centrifugation, and repeating the adsorption step on the supernatant with fresh Sepharose-gelatin two more times. This treatment resulted in the removal of $>95 \%$ of the original gelatinase in the two media as assessed by zymography. Next, the media were dialyzed at $4^{\circ} \mathrm{C}$ (membrane cutoff $12 \mathrm{kDa}$ ) against water, lyophilized, and reconstituted to the original volume with the endothelial media. The glucose concentration (measured by the glucose oxidase method) in both the reconstituted conditioned media was $10 \mathrm{mM}$ (endothelial media used for reconstitution was $10 \mathrm{mM}$ in glucose), confirming that the dialysis completely removed the HG from the original HG mesangial media. TGF- $\beta 1$ (measured by a sandwich immunoassay kit, R\&D systems, Minneapolis, MN, USA) was expectedly present in higher amounts in the original HG $(2.2 \mathrm{ng} / \mathrm{ml})$ than in NG $(1.2 \mathrm{ng} / \mathrm{ml})$ media,${ }^{6}$ but it became negligibly low $(<0.1 \mathrm{ng} / \mathrm{ml})$ in both the final reconstituted media, because TGF- $\beta 1$ is labile and was inactivated by dialysis and lyophilization during the preparation of the conditioned media. The media thus prepared were labeled as NG-CM (NG conditioned mesangial cell media) and HG-CM (HG conditioned mesangial cell media) for testing on the HUVEC. All such experiments included cell layers treated with control substances such as VEGF, angiopoietin-2 and an antagonist against VEGF receptor (recombinant mouseVEGF-R1/Flt-1 chimera) (R \& D Systems, Minneapolis, MN, USA).

\section{${ }^{3} \mathrm{H}-$ Thymidine Uptake}

Endothelial cells (HUVEC) were grown to $70 \%$ confluence. The medium was changed to basal media (EBM) containing conditioned media or control substances (VEGF, angiopoietin-2 or antagonist against VEGF receptor) and $3 \mu \mathrm{Ci} / \mathrm{ml}$ of ${ }^{3} \mathrm{H}$ thymidine (ICN, Costa Mesa, CA, USA). The cells were incubated overnight at $37^{\circ} \mathrm{C}$ in $5 \% \mathrm{CO}_{2}-95 \%$ air. The media were discarded and the cells were washed several times with ice-cold PBS to remove unincorporated ${ }^{3} \mathrm{H}$-thymidine. The cells were then 
extracted in a small volume of $0.1 \%$ SDS, and precipitated with $10 \%$ trichloroacetic acid. The precipitates were re-dissolved in $1 \mathrm{~N} \mathrm{NaOH}$ and mixed with $10 \mathrm{ml}$ of scintillation fluid, and counted in a $\beta$-counter. Unextracted cells from other wells were detached by trypsinization and counted in a counting chamber. ${ }^{3} \mathrm{H}$-thymidine uptake data were expressed as CPM/million cells.

\section{Assay for Extracellular Matrix of Endothelial Cells}

Extracellular matrix was measured as the release of peptides from cultures of HUVEC after treatment with clostridial collagenase - a powerful collagendegrading enzyme. Since clostridial collagenase may also have a protease activity, we performed preliminary experiments to establish conditions to maximize the collagenase action on the cultures with minimal protease action. Gelatin (a model collagen) and BSA (a model protein) were labeled with fluorescein isothiocyanate conjugate (FITC) as described before. $^{2}$ Each of these labeled proteins was mixed with clostridial collagenase (Sigma Chem Co., St Louis, MO, USA) in $10 \mathrm{mM}$ PBS pH 7.4 containing $1 \mathrm{mM} \mathrm{CaCl}{ }_{2}$ and $1 \mu \mathrm{M} \mathrm{ZnCl}_{2}$ (assay buffer) and incubated at $37^{\circ} \mathrm{C}$. The degradation of the FITC-albumin and FITC-gelatin was monitored by fluorescence spectroscopy (Ex $490 \mathrm{~nm}$, Em 519 nanometers). As the FITC-labeled protein was degraded there was an increased emission signal at $519 \mathrm{nM}$ due to the release of the FITC from its autoquenched state in the conjugate. We found that while gelatin was maximally degraded by clostridial collagease in $5 \mathrm{~min}$, the degradation of albumin was only complete in $30 \mathrm{~min}$ with less than $5 \%$ degraded in the first $5 \mathrm{~min}$. We then applied these conditions to the measurement of matrix in cultures of HUVEC as follows: cultures of HUVEC were washed with ice-cold assay buffer and layered with fresh buffer containing clostridial collagenase $(10 \mu \mathrm{g} / \mathrm{ml})$. The dishes were incubated at $37^{\circ} \mathrm{C}$ for $5 \mathrm{~min}$ and the buffer media were collected from the dishes. Note that there was an unnoticeable cell detachment after 5 min of incubation with clostridial collagenase. The cell supernatants were centrifuged at $3000 \mathrm{rpm}$ to remove cell debris, and their absorbance was measured at $280 \mathrm{~nm}$ in a spectrometer to quantitate the degraded peptides. Cell number was determined by cell counting from separate wells after trysinization of cell layers. The results were expressed as $\mu \mathrm{g}$ extracellular collagen/million cells.

\section{In vitro Formation of Capillaries by Endothelial Cells}

HUVEC were seeded in Lab-Tek chamber slides (Nunc, Naperville, IL, USA) prelayered with Matrigel ${ }^{\circledR}$ (diluted 1:6, $50 \mu \mathrm{l} /$ well). The cells were allowed to reach $30-50 \%$ confluence. The Matrigel-layered slides offered a three-dimensional substratum.
Media were changed to fresh media containing NG-CM or HG-CM or control substances. After 24-48 h, the cell layers were fixed with $95 \%$ ethanol and stained with Safranin O $0.1 \%$ in distilled water) for $5 \mathrm{~min}$ and de-stained with distilled water and air-dried. The capillary networks were examined by light microscopy (Nikon Corporation, New York, NY, USA).

Capillary-like openings were quantitated by counting well-formed, complete circles of endothelial cells per 12 random high-power fields $(500 \times)$ from three slides of each treatment.

\section{Induction of Diabetes in the Rats by Streptozotocin Injection}

Adult Sprague-Dawley rats (250-350g wt) were injected i.v. with a single injection of streptozotocin $(55 \mathrm{mg} / \mathrm{kg})$ (Sigma Chem Co., St Louis MO, USA) in $5 \mathrm{mM}$ acetate $\mathrm{pH} 5.0$ buffer. After $24 \mathrm{~h}$, rats were tested for blood glucose level using glucostrips (Walgren Pharmacy Deerfield, IL, USA). Animals with glucose levels above $16 \mathrm{mM}$ were considered diabetic. A group of diabetic animals were treated with $1.5 \mathrm{U}$ of insulin administered subcutaneously twice daily. Blood glucose and body weights were determined on alternate days and at the time of killing. Kidney weights were determined at the time of killing.

\section{Tissue Processing for RNA Studies and Immunoassays}

At 7 days after streptozotocin injection, the rats were anesthetized with sodium pentobarbital $(35 \mathrm{mg} / \mathrm{kg})$ and their kidneys were briefly perfused retrogradely with cold PBS (10 mM) NaCl (125 mM), pH 7.4. to remove blood. Following perfusion, the kidneys were removed and cut longitudinally to separate surgically the cortex from the medulla and papilla. Small portions of the cortex were processed for total RNA isolation as described above for RT-PCR. The larger portion of the cortex was used for the isolation of glomeruli by differential sieving in PBS containing protease inhibitors (Sigma Chem Co., St Louis, MO, USA), sonicated, and the homogenate was centrifuged at $13000 \mathrm{~g}$ for $30 \mathrm{~min}$. The clear supernatant (glomerular extract) was saved at $-20^{\circ} \mathrm{C}$ in the presence of $0.1 \%$ Triton X-100. VEGF and angiopoietin-1, -2 levels were determined in the extracts as described above and the results normalized by protein content of the extract. Protein was determined by the Bradford method (Biorad, Hercules, CA, USA). Western blotting was carried out as described before. ${ }^{32}$ using chemiluminescent detection using anti-VEGF antibody from Neomarkers ${ }^{\circledR}$ (San Ramon, CA, USA) and anti-angiopoietin-1 and -2 antibodies from Alpha Diagnostics, Inc. (San Antonio, TX, USA). 


\section{Results}

mRNA Transcripts for VEGF, Angiopoietins-1, and 2 in Rat Kidney and Cultured Mesangial Cells

To validate the role of VEGF and angiopoietins in the adult rat tissue, we tested for the presence of mRNA transcripts in rat kidney cortex and cultured mesangial cells by RT-PCR. Both cultured mesangial cells and rat glomeruli contained mRNA transcripts for all three factors, VEGF, angiopoietins-1, and 2 (Figure 1a, b). The band sizes for VEGF, angiopoietins-1, and -2 were similar in the two tissues and according to predictions based on primer design and published cDNA sequences. In the case of VEGF two bands were observed, the lower corresponding to the predicted size of $347 \mathrm{bp}$ and the higher band being in the $400 \mathrm{bp}$ region. This higher molecular weight band was not further investigated in the present study, but may be one of an insertion isoforms of rat VEGF, hitherto unknown.

\section{Changes in Vascular Factors in Diabetic Rat Glomeruli by ELISA and Western Blotting}

Studies were performed in sham-injected normal rats (control), rats made diabetic by a single injection of streptozotocin, and in diabetic animals treated with insulin (treatment control). At 1 day after the streptozotocin injection, rats were hyperglycemic ( $>22 \mathrm{mM}$ blood glucose), and this persisted throughout the period of study. The diabetic animals showed loss in body weight $(\sim 20 \%)$ and increase in kidney weight $(\sim 18 \%)$. Insulin treatment partially ameliorated these changes.

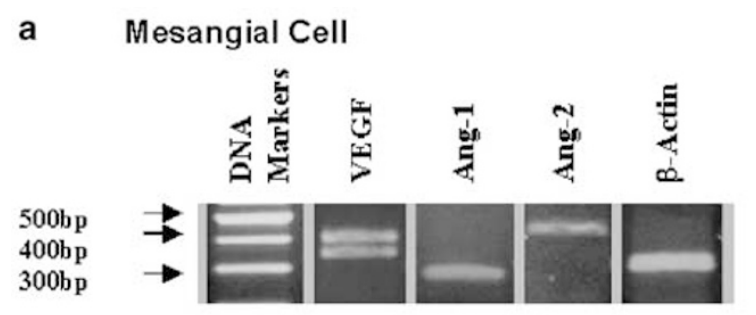

\section{b Rat Kidney Cortex}

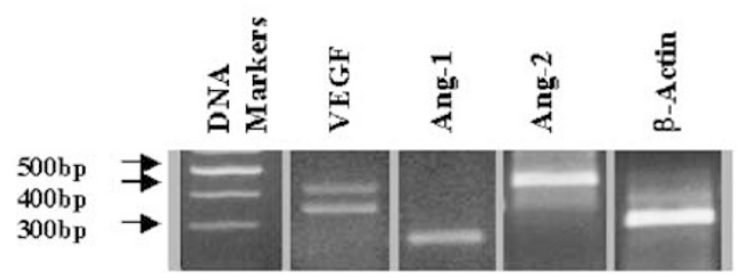

Figure 1 Detection of mRNA transcripts for vascular factors in rat kidney cortex and mesangial cells by RT-PCR. Both kidney cortex and mesangial cells contained transcripts for VEGF, angiopoietins-1, and -2. The band sizes in each case were according to predictions based on primer design and published cDNA sequences. Of the two bands of VEGF, the lower band corresponded to the predicted size of $347 \mathrm{bp}$ and the higher band in the $400 \mathrm{bp}$ region was an unknown isoform, not investigated further.
Vascular factors were measured in glomerular extracts of control, 1-week diabetic, and 1-week diabetic animals treated with insulin. These extracts represented a mixture of cellular and extracellular milieu (see Materials and methods). Following 1 week of diabetes, VEGF levels in glomeruli decreased by $38 \%$, angiopoietin-1 levels decreased by $57 \%$, and angiopoietin-2 levels increased by $318 \%$ compared to controls. In insulin-treated rats, the levels of VEGF and angiopoietin-1 normalized to control levels, but angiopoietin-2 levels remained high (ELISA results in Figure 2a-c; representative Western blots in Figure 2d).

\section{Disturbance of Vascular Factors in Mesangial Cells After Exposure to HG}

To extend the in vivo findings of changes in vascular factors in diabetic glomeruli and its impact on the endothelial cells we cultured mesangial cells for 4 days in HG (25 mM glucose) media to simulate diabetic conditions. Exposing cells to HG caused VEGF levels to decrease by $50 \%$. Angiopoietin-1 remained unchanged and angiopoietin-2 increased by $280 \%$ compared to NG (10 mM glucose) control (Figure 3a-c). In mesangial cells incubated with $10 \mathrm{mM}$ glucose $+15 \mathrm{mM}$ mannitol (osmotic control), VEGF and angiopoietin-1 and -2 levels were similar to the NG control (data not shown). The inhibition of VEGF by glucose was also tested at different glucose concentrations. In $15 \mathrm{mM}$ glucose, VEGF secretion was inhibited by $34 \%$ and at $30 \mathrm{mM}$ glucose
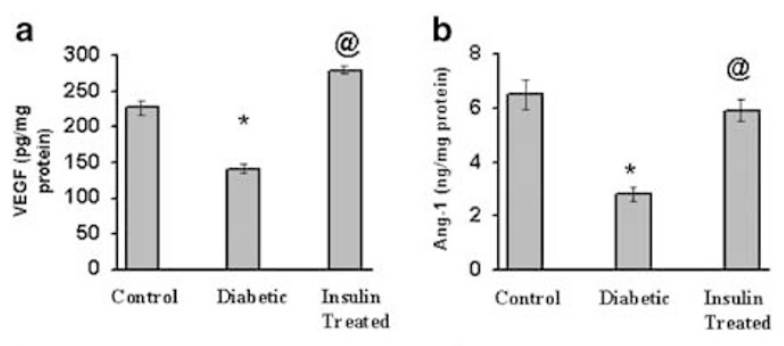

C

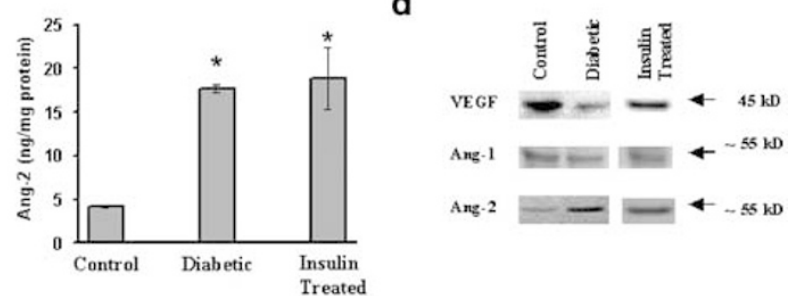

Figure 2 VEGF, angiopoietins-1, and -2 levels in control and diabetic glomeruli. Data are presented as mean \pm s.e.m.; $N=6$ in each group. ${ }^{*}$ Denotes statistical difference compared to control and @ compared to diabetic glomeruli at $P<0.05$. In diabetic glomeruli VEGF levels by ELISA decreased by $38 \%$ (a), angiopoietin-1 levels decreased by $57 \%$ (b), and angiopoietin-2 levels increased by $318 \%$ (c) above control. In insulin-treated rats the levels of VEGF and angiopoietin-1 normalized to control levels, but angiopoietin-2 levels remained high. Similar changes were seen by Western blotting (d). 
concentration it was inhibited by $50 \%$, a value similar to that observed with $25 \mathrm{mM}$ glucose (data not shown). The VEGF and angiopoietins-1 and -2 concentrations in the cell extracts were 10-20 times lower than in the media and did not change with increasing glucose concentration (data not shown), suggesting that these factors were mostly secreted by the cells and did not accumulate in the cells.

RT-PCR for the quantitation of mRNA transcripts for the vascular factors in mesangial cell mostly confirmed the changes in the protein levels (Table 1). mRNA for VEGF decreased by $27 \%$ and angiopoietin-2 increased by $523 \%$. While angiopoietin-1 protein levels were unchanged by HG, as previously observed (Figure 3b), the mRNA levels increased by $65 \%$. Thus, the changes in vascular factors elicited by glucose were similar in vivo and in vitro (except for angiopoietin-1).
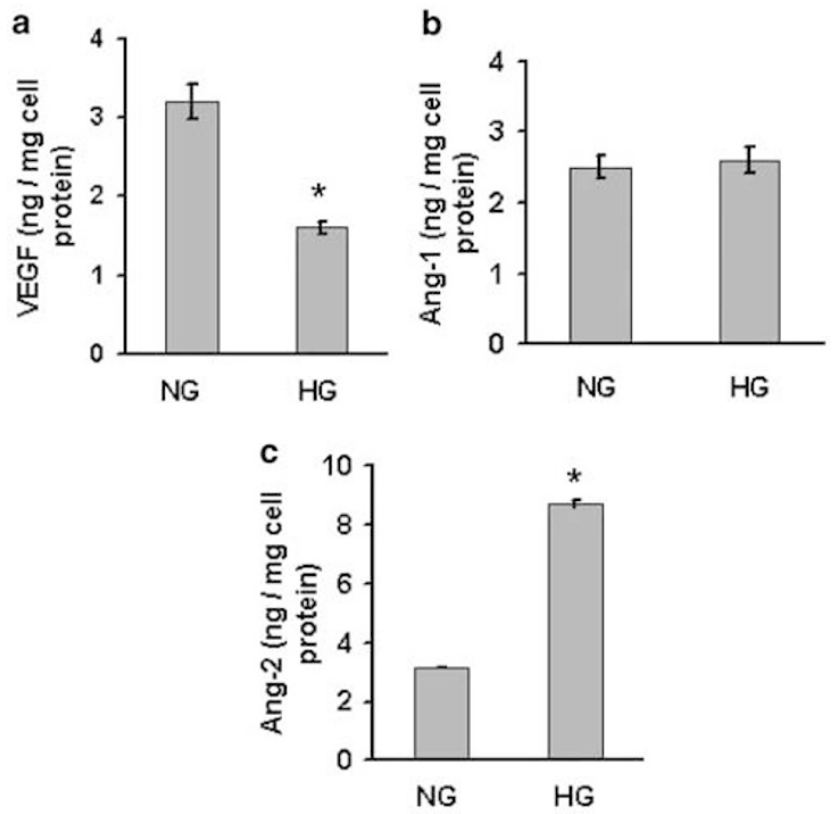

Figure 3 VEGF, angiopoietin-1, and angiopoietin-2 levels in media of mesangial cells incubated with either NG or HG. Data are presented as mean \pm s.e.m.; $N=6$ in each group. ${ }^{*}$ Denotes statistical difference between NG and HG at $P<0.05$. HG inhibited VEGF levels by $50 \%$ (a), angiopoietin-1 levels remained unchanged (b), and angiopoietin-2 levels increased to $280 \%$ above control (c).

Table 1 Image densitometry for quantitation of RT-PCR bands obtained from mesangial cells following high glucose treatment

\begin{tabular}{lcrcc}
\hline Protein & $n$ & $N G^{\mathrm{a}}$ & $H G$ & Change $($ diff $/ N G \times 100)$ \\
\hline VEGF $^{\mathrm{b}}$ & 3 & $607 \pm 22$ & $442 \pm 11$ & $27 \% * \downarrow$ \\
Ang-1 & 3 & $251 \pm 23$ & $415 \pm 16$ & $65 \% * \uparrow$ \\
Ang-2 & 3 & $21 \pm 2.3$ & $131 \pm 12$ & $523 \% * \uparrow$ \\
\hline
\end{tabular}

${ }^{\mathrm{a}}$ Numbers represent ratio: density of band/density of actin in arbitrary units with the density of actin band of HG Ang-2 set at 1000.

${ }^{\mathrm{b}}$ Of the two bands obtained by RT-PCR (see Figure 1), the lower band of $347 \mathrm{bp}$ was considered relevant and quantitated (see text).

${ }^{*} P$-value $<0.05$ compared to NG by Student's $t$-test.
The time course of the decrease in VEGF in mesangial cell media after exposure to HG was gradual until day 3 and became significant compared to NG only by day 4 (data not shown). The increase in angiopoietin-2 was similar in that until day 3 there was a gradual increase, becoming significant by day 4 (data not shown).

\section{Effect of Mesangial Cell Conditioned Media on ${ }^{3} \mathrm{H}$ - Thymidine Uptake, Extracellular Matrix, and In Vitro Capillary Formation by Endothelial Cells}

To test the effect of altered vascular factors from mesangial cell media on endothelial cell metabolism, we collected conditioned media from mesangial cells grown for 4 days either in NG-CM or HG$\mathrm{CM}$. The media were dialyzed to remove small molecules $(<12 \mathrm{kDa})$, concentrated by lyophilization and reconstituted in PBS for further processing. The two conditioned media were biochemically equalized for glucose, TGF- $\beta$, and gelatinases as described in Materials and methods in order to avoid the confounding effects of nonvascular factors. The media were finally reconstituted in the endothelial cell media (containing normal glucose) for testing on endothelial cells.

The effect of the conditioned media on the growth of endothelial cells was tested by the ${ }^{3} \mathrm{H}$-thymidine uptake assay. In the presence of HG-CM, ${ }^{3} \mathrm{H}-$ thymidine uptake by endothelial cells decreased by $61 \%$ compared to that observed in cells exposed to NG-CM (Figure 4). As the conditioned media contain a mixture of vascular factors, several controls were tested in parallel to interpret the results. These included VEGF alone, VEGF receptor antagonist to simulate low VEGF condition, angiopoietin-2 alone, and the combination of VEGF receptor antagonist and angiopoietin-2 to simulate the condition found in HG-CM as previously seen in Figure 3. VEGF alone increased ${ }^{3} \mathrm{H}$-thymidine uptake by $120 \%$; VEGF receptor antagonist and angiopoietin2 decreased ${ }^{3} \mathrm{H}$-thymidine by 60 and $59 \%$, respectively; and the combination of VEGF receptor antagonist and angiopoietin-2 further decreased ${ }^{3} \mathrm{H}$-thymidine by $70 \%$ (data not shown). Based on these findings, it is likely that the inhibition of ${ }^{3} \mathrm{H}-$ thymidine uptake observed with HG-CM was caused by the low VEGF and high angiopoietin-2 shown previously to be present in the HG-CM (see Figure 3).

As vascular factors can regulate the extracellular matrix of endothelial cells, we incubated endothelial cells with the conditioned media from mesangial cells and quantitated endothelial matrix. HG-CM increased extracellular matrix by $100 \%$ above that of NG-CM (Figure 5). VEGF alone did not cause a significant change in the extracellular matrix, but the VEGF receptor antagonist and angiopoietin-2 increased matrix by 12 and $61 \%$ respectively and the two in combination caused an 


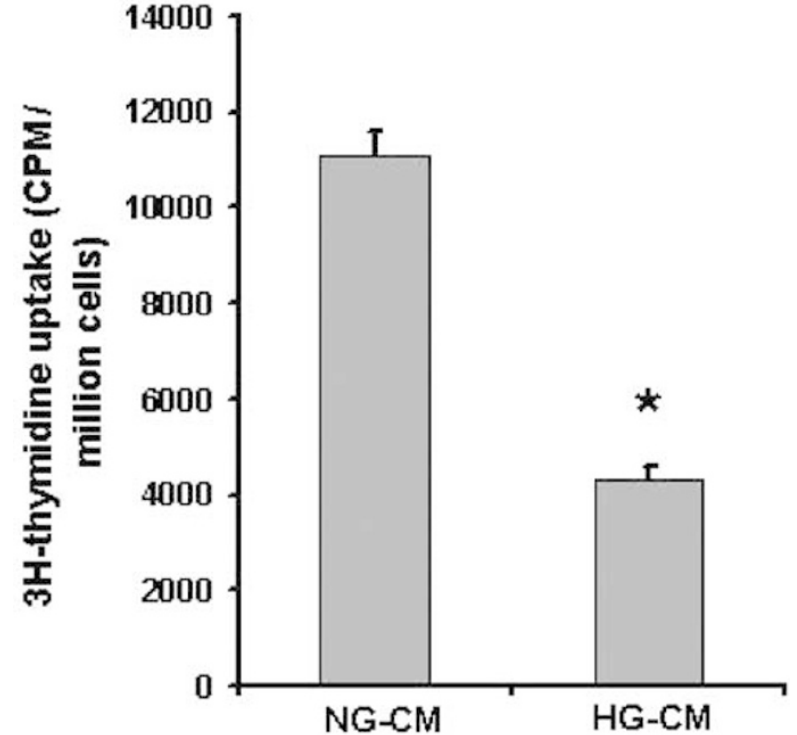

Figure 4 Effect of mesangial cell conditioned media (CM) on ${ }^{3} \mathrm{H}$-thymidine uptake by endothelial cells. Data are presented as mean \pm s.e.m.; $N=8$ in each group. ${ }^{*}$ Denotes statistical difference between NG-CM and HG-CM at $P<0.05$. In HG-CM ${ }^{3} \mathrm{H}$-thymidine uptake by endothelial cells decreased by $61 \%$ compared to that observed in cells exposed to NG-CM.

increase of $114 \%$ in extracellular matrix (data not shown). These results suggested that the increase of the endothelial matrix by HG-CM was probably due to the low VEGF and high angiopoietin-2 content in the HG-CM.

Endothelial cells form capillaries in vitro when these cells are grown on dishes coated with Matrigel $^{\circledR}$ (Figure 6a, b). Since this property is critically dependent on the balance of vascular factors, we tested the conditioned media on the in vitro capillary formation by endothelial cells. The conditioned media from NG-treated mesangial cells exerted a positive effect on the endothelial cells by promoting the in vitro capillary formation. In contrast, conditioned media from HG-treated mesangial cells inhibited capillary formation by $90 \%$ compared to capillaries formed by conditioned media from NG. VEGF and angiopoietin-2 were tested as the positive and negative controls, respectively, at concentrations of $0.625,1.25,2.5,5.0$, and $10.0 \mathrm{ng} / \mathrm{ml}$. VEGF greatly facilitated the formation of in vitro capillaries at concentrations $\geq 1.25 \mathrm{ng} / \mathrm{ml}$. Angiopoietin-2 on the other hand, inhibited the formation of capillaries at concentrations $\geq 5.0 \mathrm{ng} /$ $\mathrm{ml}$ (Figure 7). These results again suggested that the inhibition of capillary formation by HG-CM was due to the reduced VEGF and high angiopoietin-2 in the conditioned media.

\section{Discussion}

In this study, we observed that in early diabetic glomeruli and mesangial cells exposed to HG, VEGF

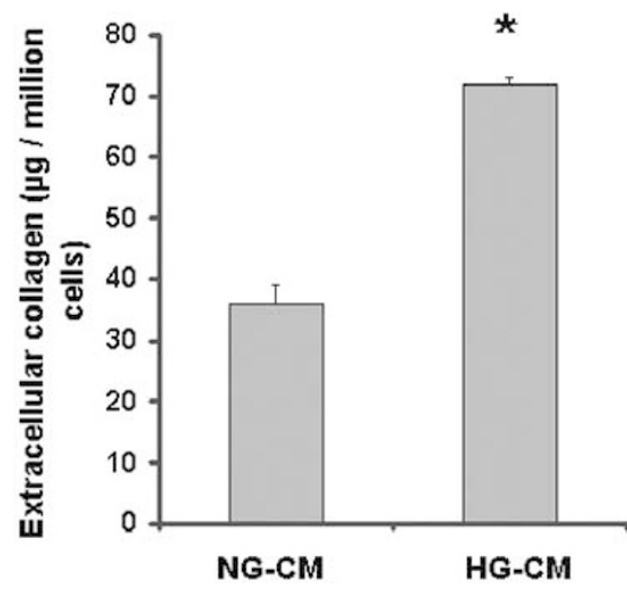

Figure 5 Effect of mesangial cell conditioned media (CM) on extracellular matrix of endothelial cells. Data are presented as mean \pm s.e.m.; $N=10$ in each group. ${ }^{*}$ Denotes statistical difference between NG-CM and HG-CM at $P<0.05$. HG-CM increased extracellular matrix by $100 \%$ above that by NG-CM.
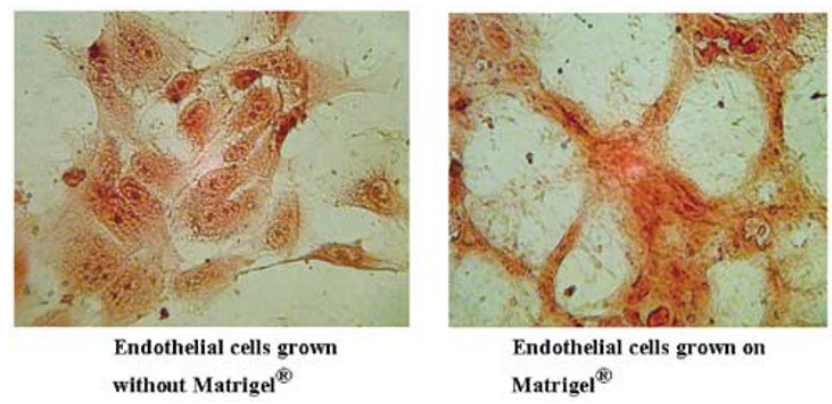

Figure 6 Endothelial cells form capillaries in vitro when grown on dishes coated with Matrigel ${ }^{\circledR}$. In the absence of Matrigel ${ }^{\circledR}$ (a), endothelial cells grow in an unorganized manner. On Matrigel ${ }^{\mathbb{R}}$ (b) the cells differentiate to form capillary-like structures.

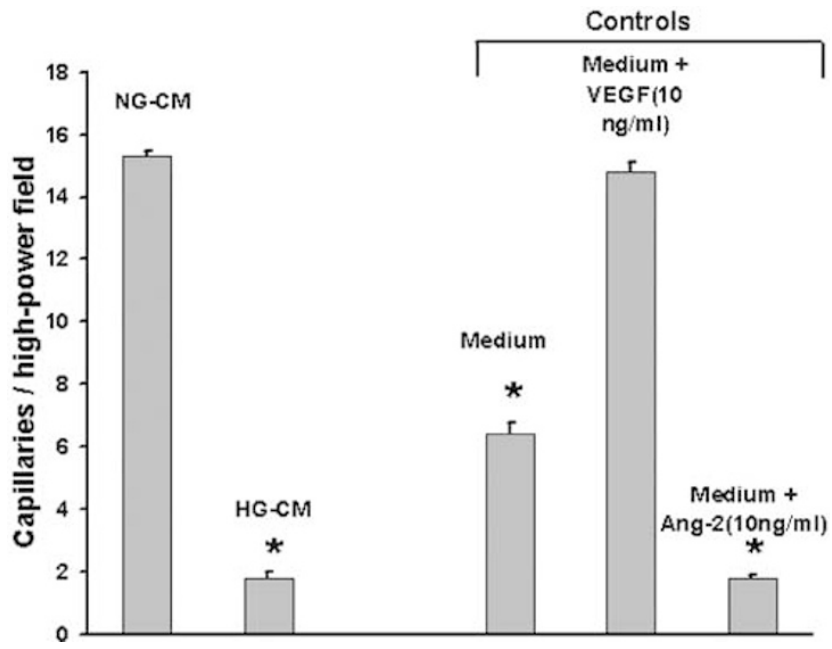

Figure 7 Effect of mesangial cell conditioned media (CM) on in vitro capillary formation by endothelial cells. Compared to media control, NG-CM exerted a positive effect on the endothelial cells by promoting in vitro capillary formation. In contrast, HG-CM inhibited capillary formation by $90 \%$ compared to NG-CM. Other controls consisting of media containing either VEGF or angiopoietin-2 were also tested. While VEGF $(10 \mathrm{ng} / \mathrm{ml})$ greatly facilitated the formation of in vitro capillaries, angiopoietin-2 (10 $\mathrm{ng} / \mathrm{ml})$ inhibited capillary formation. 
levels decreased and angiopoietin-2 levels increased. Transferring medium from HG-treated mesangial cells to cultured endothelial cells showed that this combination of low VEGF and high angiopoietin-2 affected the endothelial cells adversely. Treating endothelial cells in this manner inhibited cell proliferation, increased extracellular matrix, and disrupted capillary formation. These results provide strong evidence that HG disrupts the paracrine relationship between mesangial and endothelial cells by altering endothelial-specific vascular factors secreted by mesangial cells.

Our findings confirm earlier studies on kidney biopsies from diabetes patients and other glomerular diseases in which VEGF staining was also decreased in the glomeruli. ${ }^{21,33}$ However, this would seem to contradict an experimental study on diabetic rats in which VEGF mRNA levels in the cortex and glomeruli were increased, ${ }^{34}$ but in which VEGF protein levels in the glomerulus or kidney cortex were not measured to support the mRNA results. Our findings in the mesangial cells are also contrary to those in diabetic retinae where VEGF levels are known to be elevated. ${ }^{35}$ Such a differential tissue response to HG has also been reported in hypoxia where VEGF is increased in the lung and decreased in the kidneys. ${ }^{36}$

The differentiation of the HUVEC to form capillaries in vitro is dependent on many factors. These include vascular growth factors (VEGF, angiopoietin-1, angiopoietin-2), ${ }^{37}$ integrins, ${ }^{38}$ extracellular matrix ${ }^{39}$ and insulin. ${ }^{40}$ Since the conditioned medium from the high glucose treated mesangial cells contained an altered mixture of vascular factors, the medium was also tested for its ability to inhibit in vitro capillary formation by the endothelial cells. Indeed, the HG-CM disrupted capillary formation and resulted in looser and weaker endothelial cell associations, a finding consonant with the preponderance of antivascular factors (lower VEGF and higher angiopoietin-2) present in this medium.

One limitation of studying the effect of the rat mesangial cell media on the human endothelial cells is that these two cells originate from different species, a limitation that could not be avoided because of the known difficulty of culturing rat glomerular endothelial cells. For this reason, we chose the well-characterized HUVEC as the best endothelial cell model presently available to address the effect of HG on the paracrine interaction between mesangial cells and endothelial cells. These HUVEC are known to react to all the vascular factors we have studied, and the high crossreactivity of the murine and human angiogenic factors has been well established to make this paracrine system feasible. ${ }^{29,41-43}$ Furthermore, these cells respond to purified vascular factors to form capillary structures on matrix. ${ }^{44}$

In conclusion, we have shown that mesangial cells produce the vascular factors VEGF, angiopoie- tins-1 and -2. The medium containing these factors promotes the differentiation of endothelial cells to form capillary-like structures and therefore is pro-angiogenic in its action. In mesangial cells exposed to HG, the mixture of vascular factors changed to an antiangiogenic combination that has a negative effect on the growth and matrix of endothelial cells including disrupting their differentiation and ability to form capillary structures. In the diabetic patient glucose itself is toxic to endothelial cells ${ }^{45-47}$ but the antiangiogenic vascular growth factors secreted by mesangial cells may cause an additional disruptive effect causing endothelial injury and leading to glomerulopathy.

\section{Acknowledgement}

We are grateful to Linda Wanna MS for maintaining the endothelial cell stocks and primary mesangial cells. This work was supported by the National Kidney Foundation of Illinois and the Juvenile Diabetes Foundation International, New York, NY (JDA \# 1-2000-241). JAL Arruda and RB Robey were supported by the Merit Review Program from the US Department of Veteran Affairs.

\section{References}

1 Ayo SH, Radnik RA, Garoni JA, et al. High glucose causes an increase in extracellular matrix proteins in cultured mesangial cells. Am J Pathol 1990;136: 1339-1348.

2 Leehey DJ, Song RH, Alavi N, et al. Decreased degradative enzymes in mesangial cells cultured in high glucose media. Diabetes 1995;44:929-935.

3 Ziyadeh FN, Sharma K, Erickson M, et al. Stimulation of collagen gene expression and protein ssssynthesis in murine mesangial cells by high glucose is mediated by autocrine activation of transforming growth factor-beta. J Clin Invest 1994;93:536-542.

4 Singh R, Alavi N, Singh AK, et al. Role of angiotensin II in glucose-induced inhibition of mesangial matrix degradation. Diabetes 1999;48:2066-2073.

5 Leehey DJ, Singh AK, Alavi N, et al. Role of angiotensin II in diabetic nephropathy. Kidney Int 2000;58(Suppl 77):S93-S98.

6 Singh R, Song RH, Alavi N, et al. High glucose decreases collagenase activity in rat mesangial cells via transforming growth factor- $\beta 1$ (TGF- $\beta 1$ ). Experimental Nephrol 2001;9:249-257.

7 Yamamoto T, Nakamura T, Noble NA, et al. Diabetic kidney disease is linked to elevated expression of transforming growth factor-beta. Proc Natl Acad Sci USA 1993;90:1814-1818.

8 Maynard SE, Min J-Y, Merchan J, et al. Excess placental soluble fms-like tyrosine kinase 1 (sFlt 1) may contribute to endothelial dysfunction, hypertension, and proteinuria in preeclampsia. J Clin Invest 2003;111:649-658. 
9 Eremina V, Sood M, Haigh J, et al. Glomerular-specific alterations of VEGF-A expression lead to distinct congenital and acquired renal diseases. J Clin Invest 2003;111:707-716.

10 Sato TN, Qin Y, Kozak C, et al. TIE-1 and TIE-2 define another class of putative receptor tyrosine kinase genes expressed in early embryonic vascular system. Proc Natl Acad Sci USA 1993;90:9355-9358.

11 Sato TN, Tozawa Y, Deutsch U, et al. Distinct roles of the receptor tyrosine kinases TIE-1 and TIE-2 in blood vessel formation. Nature 1995;376:70-74.

12 Yuan HT, Suri C, Yancopoulos GD, et al. Expression of angiopoietin-1, angiopoietin-2, and the TIE-2 receptor tyrosine kinase during mouse kidney maturation. J Am Soc Nephrol 1999;10:1722-1736.

13 Yuan HT, Suri C, Landon DN, et al. Angiopoietin-2 is a site-specific factor in differentiation of mouse renal vasculature. J Am Soc Nephrol 2000;11: 1055-1066.

14 Hanahan D. Signaling vascular morphogenesis and maintenance. Science 1997;277:48-50.

15 Iijima K, Yoshikawa N, Connolly DT, et al. Human mesangial cells and peripheral blood mononuclear cells produce vascular permeability factor. Kidney International 1993;44:959-966.

16 Iruela-Arispe L, Gordon K, Hugo C, et al. Participation of glomerular endothelial cells in the capillary repair of glomerulonephritis. Am J Pathol 1995;147: 1715-1727.

17 Takahashi T, Shirasawa T, Miyake K, et al. Protein tyrosine kinases expressed in glomeruli and cultured glomerular cells: Flt-1 and VEGF expression in renal mesangial cells. Biochem Biophys Res Commun 1995;209:218-226.

18 Gruden G, Thomas S, Burt D, et al. Mechanical stretch induces vascular permeability factor in human mesangial cells: Mechanisms of signal transduction. Proc Natl Acad Sci USA 1997;94:12112-12116.

19 Noguchi K, Yoshikawa N, Ito-Kariya S, et al. Activated mesangial cells produce vascular permeability factor in early-stage mesangial proliferative glomerulonephritis. J Am Soc Nephrol 1998;9:1815-1825.

20 Brown LF, Berse B, Tognazzi K, et al. Vascular permeability factor mRNA and protein expression in human kidney. Kidney Int 1992;42:1457-1461.

21 Shulman K, Rosen K, Tognazzi K, et al. Expression of vascular permeability factor (VPF/VEGF) is altered in many glomerular diseases. J Am Soc Nephrol 1996;7:661-666.

22 Kang D-K, Joly AH, OH S-W, et al. Impaired angiogenesis in the remnant kidney model: I. Potential role of vascular endothelial growth factor and thrombospondin-1. J Am Soc Nephrol 2001;12:1434-1447.

23 Satchell SC, Harper SJ, Tooke JE, et al. Human podocytes express angiopoietin-1, a potential regulator of glomerular vascular endothelial growth factor. J Am Soc Nephrol 2002;13:544-550.

24 Simon M, Grone HJ, Johren O, et al. Expression of vascular endothelial factor and its receptors in human renal ontogenesis and in adult kidney. Am J Physiol 1995;37:F240-F250.

25 Kim B-S, Chen J, Weinstein T, et al. VEGF expression in hypoxia and hyperglycemia: Reciprocal effect on branching angiogenesis in epithelial-endothelial cocultures. J Am Soc Nephrol 2002;13:2027-2036.

26 Hoshi S, Nomoto K, Kuromitsu J, et al. High glucose induced VEGF expression via PKC and ERK in glomerular podocytes. Biochem Biophys Res Commun 2002;290:177-184.

27 Chomczynski P, Sacchi F. Single-step method of RNA isolation by acid guanidinium thiocyanate-phenolchloroform extraction. Anal Biochem 1987;162: 156-159.

28 Conn G, Bayne ML, Soderman DD, et al. Amino acid and cDNA sequences of a vascular endothelial cell mitogen that is homologous to platelet-derived growth factor. Proc Natl Acad Sci USA 1990;87: 2628-2632.

29 Davies S, Aldrich TH, Jones PF, et al. Isolation of angiopoietin-1, a ligand for the TIE2 receptor, by secretion-trap expression cloning. Cell 1996;87: 1161-1169.

30 Mandriota SJ, Pepper MS. Regulation of angiopoietin-2 mRNA levels in bovine microvascular endothelial cells by cytokines and hypoxia. Circ Res 1998; 83:852-859.

31 Nudel U, Zakat R, Shani M, et al. The nucleotide sequence of the rat cytoplasmic beta-actin gene. Nucleic Acids Res 1983;11:1759-1771.

32 Singh AK, Mo W, Dunea G, et al. Effect of glycated proteins on the matrix of glomerular epithelial cells. J Am Soc Nephrol 1998;9:802-810.

33 Bailey E, Bottomley MJ, Westwell S, et al. Vascular endothelial growth mRNA expression in minimal; change, membranous, and diabetic nephropathy demonstrated by nonisotopic in situ hybridization. J Clin Pathol 1999;52:735-738.

34 Cooper ME, Vranes D, Youssef S, et al. Increased renal expression of vascular endothelial growth factor (VEGF) expression and its receptor VEGF-R2 in experimental diabetes. Diabetes 1999;48: 2229-2239.

35 Adamis AP, Miller JW, Bernal MT, et al. Increased vascular endothelial growth factor levels in the vitreous of eyes with proliferative diabetic retinopathy. Am J Opthalmol 1994;118:445-450.

36 Marti HH, Risau W. Systemic hypoxia changes the organ-specific distribution of vascular endothelial growth factor and its receptors. Proc Natl Acad Sci USA 1998;95:15809-15814.

37 Papapetropoulos A, Garcia-Cardena G, Dengler TJ, et al. Direct actions of angiopoietin-1 on human endothelium: evidence for network stabilization, cell survival, and interaction with other angiogenic growth factors. Lab Invest 1999;79:213-223.

$38 \mathrm{Xu}$ Q, Chen X, Fu B, et al. Integrin alpha-v-beta 3-RGDS interaction mediates fibrin-induced morphological changes of glomerular endothelial cells. Kidney Int 1999;56:1413-1422.

39 Kuzuya M, Satake S, Ai S, et al. Inhibition of angiogenesis on glycated collagen lattices. Diabetologia 1998;41:491-499.

40 Yamagishi S, Kawakami T, Fujimori H, et al. Insulin stimulates the growth and tube formation of human microvascular endothelial cells through autocrine vascular endothelial growth factor. Microvascular Res 1999;57:329-339.

41 Breier G, Albrecht U, Sterrer S, et al. Expression of vascular endothelial growth factor during embryonic angiogenesis and endothelial cell differentiation. Development 1992;114:521-532.

42 Ostendorf T, Kunter U, Eitner F, et al. VEGF-165 mediates glomerular endothelial repair. J Clin Invest 1999;104:913-923. 
43 Maisonpierre PC, Suri C, Jones PF, et al. Angiopoietin2 , a natural antagonist for TIE-2 that disrupts in vivo angiogenesis. Science 1997;277:55-60.

44 Grant DS, Kinsella JL, Kibbey MC, et al. Matrigel induces thymosin $\beta 4$ gene in differentiating endothelial cells. J Cell Sci 1995;108:3685-3694.

45 Lorenzi M, Cagliero E, Toledo S. Glucose toxicity for human endothelial cells in culture. Delayed replica- tion, disturbed cell cycle, and accelerated death. Diabetes 1985;34:621-627.

46 Lorenzi M, Montisano DF, Toledo S, et al. High glucose induces DNA damage in cultured human endothelial cells. J Clin Invest 1986;77:322-325.

47 Porte Jr D, Schwartz MW. Diabetes complications: why is glucose potentially toxic? Science 1996;272: 699-700. 